Revista do SELL

v. $4, n^{\circ} .2$

ISSN: $1983-3873$

\title{
DIMENSÕES ESPECULARES EM A PAIXÃO SEGUNDO G.H., DE CLARICE LISPECTOR
}

\author{
SPECULAR DIMENSIONS IN THE PASSION ACCORDING TO G.H, BY CLARICE \\ LISPECTOR
}

\author{
Mariângela Alonso \\ UNESP - Araraquara
}

RESUMO: Expandindo-se para além dos espaços ficcionais, a obra de Clarice Lispector (1920-1977) caracteriza-se pela recusa à narrativa fechada e acabada ao buscar formas líquidas e inconclusas, que perpetuamente se desmancham para novamente se construírem. É o caso do romance $A$ paixão segundo G.H, publicado em 1964. Nesta obra, a massa textual assinala a intersecção en abyme de encadeamentos significativos diversos, um intrigante jogo narrativo especular, percorrendo um itinerário poético e labiríntico. A estrutura dos capítulos é marcada por um recurso técnico original, em que cada última frase de um capítulo se repete como a primeira do seguinte, num sinal de continuidade e retomada, ao modo de rimas dispostas em uma poesia. A repetição das frases potencializa o efeito de circularidade e o movimento de consciência da personagem G.H, que se apresenta desorganizada. Em linhas gerais, buscamos empreender um caminho possível de análise ao romance mencionado, guiando-nos pelos estudos de Gérard Genette (1982), Jean-Yves Tadié (1978), Lucien Dallenbach (1979), Laurent Jenny (1979), entre outros.

PALAVRAS-CHAVE: Circularidade; Mise en abyme; Clarice Lispector.

ABSTRACT: Expanding beyond the fictional spaces, the work of Clarice Lispector (19201977 ) is characterized by refusal to narrative closed and finished to look unfinished and liquid forms, which perpetually crumble in order to be built up again. This is the case of the novel The passion according to GH, published in 1964. In this work, the textual mass marks the intersection en abyme with significant number of threads, an intriguing specular narrative game, walking a labyrinth, and poetic itinerary. The structure of the chapters is marked by a unique technical feature, where every last sentence of a chapter repeats the following one as the first, a sign of continuity and resumption, when arranged in order of rhyming in a poetry. The repetition of statements potentializes the circularity effects as well as G.H. character's movements of awareness, which shows disorganized by itself. In general, we seek to undertake an analysis of a possible analysis path for the mentioned novel, guiding us through studies of Gérard Genette (1982), Jean-Yves Tadié (1978), Lucien Dallenbach (1979), Laurent Jenny (1979), among others.

KEYWORDS: Circularity; Mise en abyme; Clarice Lispector. 


\section{Revista do SELL \\ v. $4, n^{\circ} .2$ \\ ISSN: $1983-3873$}

\section{Introdução}

A Modernidade foi palco da presença do "eu" do narrador realizada inicialmente pelo Romantismo e pelo Simbolismo. Ao contrário dos narradores do século XIX, a ficção moderna é caracterizada pelo emprego cada vez mais frequente do foco narrativo em primeira pessoa. A obra A paixão segundo G.H., de Clarice Lispector enquadra-se perfeitamente nesta perspectiva.

Publicada em 1964, essa narrativa atraiu o leitor pela problematização presente em sua linguagem e pelo estranhamento causado pelos motivos existenciais. Para Benedito Nunes o livro "[...] condensa a linha interiorizada de criação ficcional que Clarice Lispector adotou desde o seu primeiro romance [...]" (NUNES, 1988, p. 24).

A perspectiva de escrita introspectiva ultrapassa os domínios da expressão verbal, pois a escritora leva às últimas consequências a experiência de exprimir o que não pode ser inteiramente verbalizado, na tentativa de recuperar o transe que a todo momento cria barreiras ao relato da personagem no encontro com uma outra verdade, "despojando-se, para tanto, da linguagem, de sua capa protetora" (KANAAN, 2003, p. 139).

A narração gravita em torno dos passos que a personagem G.H. dá em seu apartamento, metáfora da peregrinação de ordem interior, a partir da decisão rotineira de arrumá-lo. No quarto da empregada, último cômodo de sua casa e primeiro a ser "arrumado", a personagem defronta-se com uma barata, ser que estabelece o ponto de partida para uma longa introspecção: "[...] ter descoberto súbita vida na nudez do quarto me assustara como seu eu descobrisse que o quarto morto era na verdade potente" (LISPECTOR, 1998, p. 47).

A massa textual assinala a intersecção de encadeamentos significativos diversos, isto é, um intrigante jogo narrativo especular, percorrendo um itinerário poético e labiríntico. O poético aí se apresenta em todos os níveis, desde a linguagem, marcada por um traço sumamente polissêmico, até as referências de tempo e espaço, na medida em que ganham a multiplicidade de sentidos.

Expandindo-se para além dos espaços ficcionais, a obra caracteriza-se pela recusa à narrativa fechada e acabada ao buscar formas líquidas e inconclusas, que perpetuamente se desmancham para novamente se construírem, num movimento circular, restando à autora tecer e destecer o texto num contínuo entrelaçamento. 


\section{Revista do SELL}

v. $4, n^{\circ} .2$

ISSN: $1983-3873$

Instaura-se, portanto, o movimento de eterno retorno, ou seja, uma travessia simbólica e ontológica, vivida por G.H., no desejo de conhecer-se.

Em linhas gerais, buscamos empreender um caminho possível de análise ao romance mencionado, guiando-nos pelos estudos de Gérard Genette (1982), Jean-Yves Tadié (1978), Lucien Dallenbach (1979), Laurent Jenny (1979), entre outros.

\section{Dimensões especulares}

"O que é um espelho? Não existe a palavra espelho - só espelhos, pois um único é uma infinidade de espelhos".

Clarice Lispector

A efervescência cultural, política e social da década de 60 favoreceu o ambiente de receptividade ao romance $A$ paixão segundo $G$.H, bem como um prestígio literário já conquistado por Clarice Lispector, que publicara também em 1964 os contos e crônicas do volume $A$ legião estrangeira. Alguns críticos reformularam posições anteriores, reconhecendo a importância da proposta inovadora, ou mesmo, transgressora, da autora no âmbito de nossas letras: "[...] na codificação literária, a crítica a partir de instrumental diverso, procurava destacar a elaboração artística do romance e a sua importante posição dentro da prosa de ficção nacional" (JUNIOR; CAMPEDELLI, 1988, p. 202-203).

De acordo com Nádia Battella Gotlib, A paixão segundo G.H. reúne de forma concêntrica duas tendências que vinham sendo experimentadas em obras anteriores: de um lado o tema das relações entre os seres, de outro, a estrutura narrativa típica de alguns contos, em que o processo de escrita é gradativamente desenvolvido por etapas definidas, representando "[...] dualidades em cotejo, embatendo-se, uma, o contrário da outra, até um ponto de encontro e de contato, a partir do qual continuam seu percurso, especularmente, no avesso, no contrário, excluindo-se e identificando-se [...]" (GOTLIB, 1988, p. 173).

Trata-se da primeira obra de Clarice Lispector em primeira pessoa, uma verdadeira confissão da experiência vivida no dia anterior ao instante do discurso e que perturbou para sempre a protagonista G.H.

No primeiro capítulo há uma espécie de síntese dos temas que serão desdobrados no decorrer da obra. A visão reflexiva de G.H. em busca de um sentido existencial se 


\section{Revista do SELL}

v. $4, n^{\circ} .2$

ISSN: $1983-3873$

traduz por meio de comentários, perguntas e interpretações sobre Deus, a beleza, a linguagem, a arte, a vida entre outros temas. Conforme Benedito Nunes, "antes de ser mística, a visão de G.H. pertence ao misticismo da escrita" (NUNES, 1988, p. 28), ou seja, uma espécie de escrita de fascinação como método empírico de indagação metafísica.

Esse capítulo, assemelhando-se a um prólogo que antecede a ação, já apresenta a ação da personagem em pleno andamento, como evidenciam os seis travessões que iniciam o texto, cujas primeiras palavras indicam a busca da personagem:

estou procurando, estou procurando. Estou tentando entender. Tentando dar a alguém o que vivi e não sei a quem, mas não quero ficar com o que vivi. Não sei o que fazer do que vivi, tenho medo dessa desorganização profunda. Não confio no que me aconteceu. Aconteceume alguma coisa que eu, pelo fato de não a saber como viver, vivi uma outra? [...] (LISPECTOR, 1998, p.11)

Buscando o seu autoconhecimento, a personagem G.H segue o movimento de sua própria imagem: "Eu vivia mais dentro de um espelho. Dois minutos depois de nascer eu já havia perdido as minhas origens" (LISPECTOR, 1998, p. 28).

A imagem do espelho remete-nos de imediato aos estudos de Gilbert Durand. Para o estudioso, o espelho é parte importante do "processo de desdobramento das imagens do eu" (DURAND, 1997, p. 100). Ligando-se à água, a especularidade é concebida por Durand juntamente à imagem de Ofélia, trágica personagem shakesperiana, bem como dos mitos de Acteão e Narciso.

Ao mirar-se na barata, G.H. ocupa o espaço errante do sujeito que se procura, extremado no "drama da linguagem" (NUNES, 1995, p. 76). O enredo clariceano traduz, assim, o "desapossamento" e a reconquista de um eu.

O encontro de G.H. com a barata é permeado pelo movimento especular de identificação. A personagem passa a conhecer o outro e consequentemente, a conhecerse:

Eu, corpo neutro de barata, eu com uma vida que finalmente não me escapa pois enfim a vejo fora de mim - eu sou a barata, sou minha perna, sou meus cabelos, sou o trecho de luz mais branca no reboco da parede sou cada pedaço infernal de mim - a vida em mim é tão insistente que se me partirem, como a uma lagartixa, os pedaços continuarão estremecendo e se mexendo. Sou o silêncio gravado numa parede, e a borboleta mais antiga esvoaça e me defronta: a mesma de sempre. De nascer até morrer é o que eu me chamo de humana, e nunca propriamente morrerei. (LISPECTOR, 1998, p. 65) 


\section{Revista do SELL \\ v. $4, n^{\circ} .2$}

ISSN: $1983-3873$

A narrativa apresenta, portanto, uma espécie de permutação entre eu x barata, na medida em que recobre tanto a existência humana quanto a animal (TASCA, 1988, p. 276).

Desse modo, a protagonista engendra um relato dificultoso em que revela criar o acontecimento por meio da escrita, uma vez que o momento da vivência lhe foge ao controle: "Vou criar o que me aconteceu. Só porque viver não é relatável. Criar sim, mentir não. Criar não é imaginação, é correr o grande risco de se ter a realidade" (LISPECTOR, 1998, p. 21).

Ao comentar o apartamento, ou seja, a casa onde em "semiluxo" vive, G.H. explicita um espaço de contrastes e de poder: "O apartamento me reflete. [...] Pessoas de meu ambiente procuram morar na chamada 'cobertura'. É bem mais que uma elegância. É um verdadeiro prazer: de lá domina-se uma cidade" (LISPECTOR, 1998, p. 30).

Não se trata de uma relação fictícia com o apartamento, mas de uma cumplicidade nos momentos indivisíveis da consciência refletida em cada cômodo visitado pela protagonista. O caminho de G.H. é trilhado no sacrifício de buscar sua identidade, ao encontro de uma experiência transgressora: "Tudo aqui se refere na verdade a uma vida que se fosse real não me serviria. O que decalca ela, então? Real, eu não a entenderia, mas gosto da duplicata e a entendo. A cópia é sempre bonita" (LISPECTOR, 1998, p. 30).

A relação de G.H com o apartamento, calcada na cópia, na duplicata do ambiente, contribui sorrateiramente para o entendimento em torno da movência especular dos textos, elemento constante no processo de criação de Clarice Lispector. Assim é que persiste a imagem da barata, retornando nesse romance ao resistir à nudez do quarto, à nudez da casa minuciosamente desinfetada:

Era uma cara sem contorno. As antenas saíam em bigodes dos lados da boca. A boca marrom era bem delineada. Os finos e longos bigodes mexiam-se lentos e secos. Seus olhos pretos facetados olhavam. Era uma barata tão velha como um peixe fossilizado. Era uma barata tão velha como salamandras e quimeras e grifos e leviatãs. Ela era antiga como uma lenda. Olhei a boca: lá estava a boca real. (LISPECTOR, 1998, p. 55)

No confronto com a barata, o que se expõe é a matéria que a assusta e lhe foge ao controle. Conforme sinaliza Nádia Gotlib:

As tantas camadas de sentido que a narradora vai descascando, tal como as 'cascas' da barata, desenham, na própria estrutura da obra, o desvencilhar-se do convencional em direção ao original, dando voz ao feio, seco, mágico, difícil. (GOTLIB, 1988, p. 174-175) 


\section{Revista do SELL}

v. $4, n^{\circ} .2$

ISSN: $1983-3873$

A ideia de Gotlib em torno das "camadas de sentido" ligadas às "cascas da barata" é útil para pensarmos o mecanismo textual de espelhamento do texto clariceano à semelhança das bonecas russas (matryoshkas) e das caixas chinesas, acopladas umas dentro das outras, em sinal de infinita retomada. Tal procedimento remete à multiplicidade textual discutida por Roland Barthes: "[...] um texto não é feito de uma linha de palavras a produzir um sentido único, de certa maneira teológico, mas um espaço de dimensões múltiplas, onde se contestam escrituras variadas" (BARTHES, 2004, p. 62).

A caracterização que G.H. faz da barata vai se sobrepondo especularmente à imagem da empregada Janair, ou seja, um rosto sem contorno, com a boca marrom e os olhos pretos, que mesmo ausente permanece no quarto:

[...] arrepiei-me ao descobrir que até agora eu não havia percebido que aquela mulher era uma invisível. Janair tinha quase que apenas a forma exterior, os traços que ficavam dentro de sua forma eram tão apurados que mal existiam: ela era achatada como um baixo-relevo preso a uma tábua. (LISPECTOR, 1998c, p. 41)

Janair permanece presente na interioridade de G.H., ao modo de uma cópia revisitada. Como escultora que é, G.H. tenta dar forma ao caracterizar a empregada. A descrição concedida lembra as formas de uma barata, mais especificamente a que foi encontrada no armário: achatada, de baixo-relevo e de cor escura.

A autora funde a técnica da prosa e da poesia para relatar, em primeira pessoa, a viagem mítica da personagem G.H. pelo espaço labiríntico de seu apartamento. Assim, altamente simbólica e polissêmica, a estruturação dos capítulos conta com um recurso técnico original, utilizado na narrativa: cada última frase de um capítulo se repete como a primeira do capítulo seguinte, num sinal de continuidade e retomada, ao modo de rimas dispostas em uma poesia:

Capítulo I: "É que um mundo todo vivo tem a força de um Inferno". (LISPECTOR, 1998, p. 22)

Capítulo II: "É que um mundo todo vivo tem a força de um Inferno". (LISPECTOR, 1998, p. 23)

Capítulo III: "[...] só eu saberei se foi a falha necessária" (LISPECTOR, 1998, p. 32).

Capítulo IV: "[...] só eu saberei se foi a falha necessária" (LISPECTOR, 1998, p. 33).

Tal recurso revela a faceta mitopoética postulada pelo gênero da narrativa poética. O francês Jean-Yves Tadié, ao discorrer sobre esta última, explica-nos este fenômeno: 


\section{Revista do SELL}

v. $4, n^{\circ} .2$

ISSN: $1983-3873$

[...] il y a là un conflit constant entre la fonction référentielle, avec ses tâches d'évocation et de représentation, et la fonction poétique, qui attire l'attention sur la forme même du message. Si nous reconnaissons, avec Jakobson, que la poésie commence aux parallélismes, nous trouverons, dans le récit poétique, un système d'echos, de reprises, de contrastes qui sont l'équivalent, à grande échelle, des assonances, des allitérations, des rimes [...] (TADIÉ, 1978, p. 8)

Retomando Jakobson, Tadié chama a atenção para a função poética da linguagem, ao confrontar os procedimentos da narração com a poesia. Ele observa o fato de que a função poética assume, nas narrativas poéticas, um papel bem mais relevante que a referencial. Assim:

Dans le récit mythique et poétique, le monde est après le récit, qui postule son incarnation. II s'agit moins de dénoter, ou de connoter, que de susciter. L'engagement du récit poétique apparaît ici clairement: mais ce qu'il propose de changer, c'est la condition humaine de l'individu, non as condition politique ou sociale. (TADIÉ, 1978, p. 158)

Como se vê, diferentemente das narrativas realistas, as narrativas poéticas trazem, como tema central, questões inerentes à condição humana. Seus personagens efetuam, muitas vezes, uma busca frequente, de aspecto existencial. Tais narrativas assemelhamse às narrativas míticas, na medida em que recriam o mundo através de símbolos, oferecendo, portanto, possibilidades de questionamento, numa busca incessante e eterna.

Nesse sentido, o encadeamento em corrente de $A$ paixão segundo G.H. sela "[...] o compromisso estrutural de uma sequência densa, em que cada elo tem seu peso no processo de "aproximação" de algo que se procura e que se encontra" (GOTLIB, 1995, p. 358).

Para Olga de Sá, esse recurso funciona como uma linha curva e contínua, conferindo à introspecção de G.H. "[...] um aspecto de ininterrupta continuidade e à voz de sua narrativa, uma tonalidade de canção, como as velhas cantigas medievais" (SÁ, 2000, p. 259). Evidencia-se em tais cantigas, o paralelismo das estrofes, a técnica do leixa-pren, ou seja, "processo de composição improvisada, que obriga um dos improvisadores a repetir o último verso do outro, para o qual devia achar seqüência" (SARAIVA ; LOPES, 1969, p. 50).

O retorno das frases cria um efeito alucinatório constante, no qual a repetição pode sugerir o movimento mítico do eterno retorno, ou seja, a percepção da circularidade, fato que remete ao constante re-início da escrita e da experiência, semelhante ao circuito do "tempo-serpente" que morde incessantemente sua própria cauda, em movimento de 


\section{Revista do SELL}

v. $4, n^{\circ} .2$

ISSN: $1983-3873$

eterna busca, de conclusão impossível, conforme salienta Octavio Paz: "[...] apresenta-se como um círculo ou uma esfera - algo que se fecha sobre si mesmo, universo autosuficiente no qual o fim é também o princípio [...]" (PAZ, 1995, p. 83).

No estudo intitulado Mosaïques: um objet esthétique à rebondissements, Lucien Dallenbach (2001) atenta para uma espécie de mosaico, caracterizado pela mistura de fragmentos e contaminação de gêneros presente na escrita de obras como Ulisses, de James Joyce e Mrs. Dalloway, de Virginia Woolf. Em tais narrativas, prosa e poesia imbricam-se, tomando diferentes atalhos, porém, ocupando um mesmo itinerário poético. É igualmente por meio de um intrigante mosaico de prosa e poesia que a estrutura de $A$ paixão segundo G.H. se arquiteta, no constante exercício de testar as potencialidades e os limites da própria linguagem: "A linguagem é o meu esforço humano. Por destino tenho que ir buscar e por destino volto com as mãos vazias" (LISPECTOR, 1998, p. 176).

A rede de conexões entre prosa e poesia levam-nos aos estudos de Laurent Jenny (1979) acerca do fenômeno da intertextualidade, situado em sua multiplicidade, essencialmente ligado à poeticidade e à evolução literária. Para Jenny, a dinâmica entre textos é caracterizada pela "recusa do ponto final que poderia fechar o sentido e paralisar a forma" (JENNY, 1979, p. 42).

Nesse processo, a estrutura do encaixe toma corpo, com a repetição das frases: "[...] cada uma delas remete à outra, numa série de reflexos que não pode chegar ao fim, salvo se tornar eterna: assim por auto-encaixe" (TODOROV, 1969, p. 132).

Como procedimento narrativo, o encaixe constitui "[...] uma explicitação da propriedade mais profunda de toda narrativa" (TODOROV, 1969, p. 12). Ao enredar frases que se repetem, a narrativa clariceana acaba incidindo-se na sua própria imagem. Tal resumo intratextual ou "repetição interna" constitui-se na desarticulação da massa textual, intervindo na rede de relações, de modo a assinalar encadeamentos significativos diversos, isto é, um intrigante jogo narrativo especular denominado mise en abyme.

A técnica da mise en abyme caracteriza-se como uma das formas mais empregadas pela literatura no objetivo de refletir sobre si mesma, ou seja, um processo de autoreflexão, discutido pelo escritor André Gide em $1893^{1}$.

\footnotetext{
${ }^{1}$ No entanto, foi Victor Hugo, ao estudar a obra de Shakespeare, quem primeiro observou essa técnica. Hugo notou que, com exceção de Romeu e Julieta e Macbeth, em todas as demais peças do autor de Hamlet encontra-se uma espécie de dupla ação que cruza o drama, refletindo-o numa dimensão menor. Cf. HUGO, Victor. William Shakespeare. Tradução de Renata Cordeiro e Paulo Schmidt. Londrina: Campanário, 2000.
} 


\section{Revista do SELL}

v. $4, n^{\circ} .2$

ISSN: $1983-3873$

A imagem en abyme que seduz Gide é oriunda da heráldica e representa um escudo contendo em seu centro uma miniatura de si mesma, de modo a indicar um processo de profundidade e infinito, o que parece sugerir, no campo literário, noções de reflexo, espelhamento:

Gosto bastante que em uma obra de arte se reencontre, transposto à escala dos personagens, o tema mesmo desta obra. [...] na literatura, no Hamlet, a cena da comédia, e em tantas outras peças. No Wilhem Meister, as cenas de marionetes e da festa no castelo. Em A queda da casa de Usher a leitura que se faz a Roderich, etc. Nenhum desses exemplos não são absolutamente corretos. O que o seria muito mais, o que diria melhor o que quis nos meus Cahiers, no meu Narcisse e na Tentative, é a comparação com este procedimento do brasão que consiste em colocar, no primeiro, um segundo 'en abyme' (GIDE apud GARCIA, 2008, p. 128)

Em Le récit spéculaire: essai sur la mise en abyme, Dallenbach (1977) assinala: "le procédé gidien, imité plus tard par Huxley, permet selon notre critique de construire un sur-roman ouvert qui se définit par le fait que toutes ses significations possibles forment un ensemble infini" (DALLENBACH, 1977, p. 33).

Semelhante aos espelhos convexos na pintura flamenga, os quais atribuem novas dimensões aos espaços frontais e demarcados das telas, na narrativa há, por sua, vez, o desdobramento de histórias encaixadas, alargando o processo de significação textual: "Ce qu'il y a lieu d'abord de mettre em évidence, c'est que l'ouvre d'art réflexive est une représentation, et une répresentation douée d'um grand pouvoir de cohésion interne" (DALLENBACH, 1977, p. 95).

O entendimento do vocábulo mise en abyme perpassa, na escala de personagens da obra literária, o redobramento do próprio sujeito da narrativa, num movimento reflexivo:

[...] constitui um enunciado que se refere a outro enunciado - e, portanto, uma marca do código metalinguístico; enquanto parte integrante da fiç̧ão que resume, torna-se o instrumento dum regresso e dá origem, por consequência, a uma repetição interna. (DALLENBACH, 1979, p. 54)

A partir das ideias de Andre Gide, especialmente da obra Les faux-monnayeurs (1926), Dällenbach discute a estrutura abismal da técnica da mise en abyme. Nessa narrativa, Gide nos apresenta o esforço do romancista Edouard, personagem que está em fase de redação de um romance, que, por sua vez, traz título homônimo ao romance de Gide, pondo em cheque a reflexão sobre o modo e a forma da construção do texto:

Compreendam-me, eu gostaria de fazer entrar tudo nesse romance. Sem golpes de tesoura para interromper aqui ou ali, sua substância. [...] O que quero é apresentar de um lado a realidade, apresentar de outro lado esse esforço para estilizá-la, de que Ihes falava há pouco. [...] Para obter este efeito, veja, invento um personagem de romancista, que coloco como 


\section{Revista do SELL}

v. $4, n^{\circ} .2$

ISSN: $1983-3873$

figura central, e o tema do livro, se quiser, é precisamente a luta entre o que the oferece a realidade e aquilo que ele pretende fazer com isto. (GIDE, 1983, p. 166-167)

No processo metalinguístico, o autor encontra-se como produtor inscrito do texto literário, capaz de promover e articular mudanças sociais por meio de seus leitores. É mediante esse ponto de vista que o escritor do século XX buscou novos modos de narrar, de apreender a realidade e o homem. Conforme observa Alain Goulet:

Em effet, le phénomène de l'auteur en abyme tient à la fois à la nécessité, pour l'auteur, d'éclairer l'enigme de soi-même pour soi, de comprendre son monde et sa place dans son monde, et aussi à son désir d'explorer sa possibilite d'action et d'intervention dans le monde" (GOULET, 2006, p. 39)

Ainda que não seja o corpus escolhido para o presente artigo, lembramos a estrutura narrativa concêntrica e espiralada do conto "A quinta história"². Nesse texto, cinco estórias ilustram uma espécie de jogo de espelhos ou mise en abyme, repetindo instigantes estruturas temáticas. Clarice Lispector constrói em poucos parágrafos variações sobre um mesmo argumento, uma espécie de desdobramento de histórias que se sucedem, a partir de um mesmo ponto, como matar baratas:

Esta história poderia chamar-se 'As estátuas'. Outro nome possível é 'O assassinato'. E também 'Como matar baratas'. Farei então pelo menos três histórias, verdadeiras, porque nenhuma delas mente a outra. Embora uma única, seriam mil e uma, se mil e uma noites me dessem. (LISPECTOR, 1999a, p. 74)

A invocação dos contos árabes de As mil e uma noites torna claro o processo de desdobramento da narrativa clariceana, que contará com a iteração obsessiva de uma mesma história encaixada, com o acréscimo de novas imagens e a multiplicação de títulos: "as quatro ou mais possíveis histórias desencaixadas correspondem a uma só história, que se desdobrou em cadeias autônomas de significantes, como unidades narrativas mínimas" (NUNES, 1995, p. 95).

Por meio do efeito da mise en abyme o conto "A quinta história" aponta para a eternidade das histórias que retornam, assumindo uma tensão conflitiva frente ao leitor, exibindo a morte implacável como desejo maior:

As variações sobre o mesmo tema ganham a dimensão de um quadro de Escher, cujos jogos de ilusão de ótica abrem caminhos que parecem

${ }^{2}$ cf. ALONSO, Mariângela; LEITE, Guacira Marcondes Machado. Um labirinto de baratas ou 'A quinta história', de Clarice Lispector. Alere. Tangará da serra, UNEMAT, v. 04, 2001, p. 79-97. 


\section{Revista do SELL}

v. $4, n^{\circ} .2$

ISSN: $1983-3873$

descer, mas ascendem; outros que se espelham qual labirintos, terminando em becos sem saída. (ROSENBAUM, 1999, p. 133)

A referência à arte de Maurits Cornelis Escher (1898-1972) é bastante produtiva para o entendimento deste trabalho, uma vez que o artista opta, em suas telas, pela divisão regular do plano em figuras geométricas que se transfiguram, se repetem e se refletem por curiosas pavimentações e ilusões de ópticas. As figuras são entrelaçadas em formas e imagens espelhadas, apresentando-se, na maioria das vezes, em preto e branco para potencializar o efeito de dimensões improváveis:

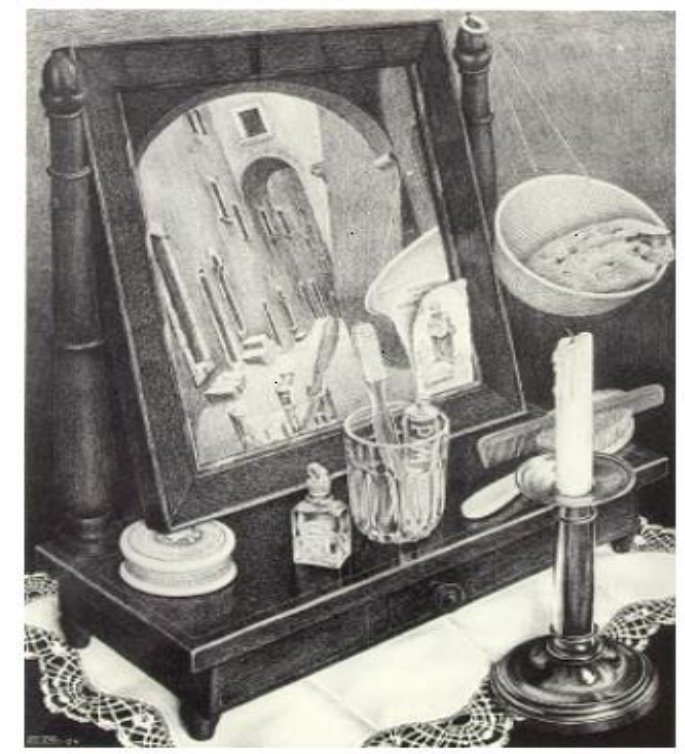

FIGURA 1. ESCHER, M. C. Natureza morta com espelho (litografia), 1934. 39.2 x 28.7 $\mathrm{cm}$, Escher Museum, The Hague, Netherlands.

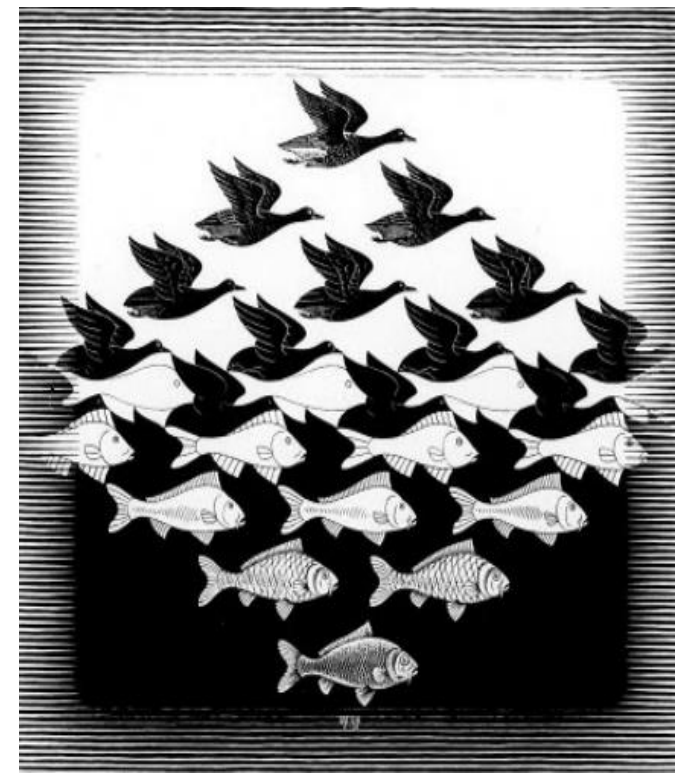

FIGURA 2. ESCHER, M. C. Ar e água I (xilogravura), 1938. 43.8 x $43.8 \mathrm{~cm}$, Escher Museum, The Hague, Netherlands.

No primeiro grafismo, diferentes espaços são retratados no espelho ligeiramente inclinado: a cena de rua é trazida para o local interno por meio do reflexo, numa curiosa combinação de perspectivas. Já no segundo, peixes brancos ascendem do fundo negro da água em direção ao céu. Ultrapassada a linha divisória entre céu e água, uma sutil transformação ocorre e os peixes ganham a forma de pássaros. Neste limiar imaginário, aves e peixes coexistem.

Como se vê, a arte de Escher explora possibilidades contidas em espaços labirinticamente interligados, oferecendo ao expectador movimentos de eternidade e infinito. Do mesmo modo, Clarice Lispector recria, por meio da reduplicação interna, o labirinto da escrita de "A quinta história", numa forte capacidade reflexiva, instaurando o 


\section{Revista do SELL}

v. $4, n^{\circ} .2$

ISSN: $1983-3873$

movimento do sujeito que se procura. Neste jogo de espelhos estilhaçados pelo mesmo enredo, "o novo envelhece e o velho se renova continuamente ao longo dos tempos" (KAHN, 2005, p. 37).

Em Palimpsestes: la litterature au second degré (1982), o teórico Gérard Genette oferece importante contribuição no que tange aos estudos de transtextualidade ou transcendência textual, que explica do seguinte modo: "tudo o que o coloca (o texto) em relação, manifesta ou secreta, com outros textos" (GENETTE, 1982, p. 7).

Ao apresentar as possibilidades de transformação textual, Genette põe em ordem duas operações: a redução e o acréscimo ou amplificação. Essa última pode ser caracterizada por uma espécie de dilatação estilística, em que o ato de duplicar ou triplicar frases de um hipotexto se faz presente. A esse respeito, a obra Moyse sauvé (1643), de Saint-Amant (1594-1661) é lembrada por Genette. Há aí uma intrigante ampliação das poucas linhas do Gênese para seis mil versos na obra de Saint-Amant.

Da mesma forma, a obra de Clarice Lispector vivenciou ao mesmo tempo, um ato lúdico e reflexivo ao ampliar e multiplicar a imagem das baratas em "A quinta história", com a dilatação de detalhes e dramas que culminaram no romance $A$ paixão segundo G.H., publicado, sintomaticamente, no mesmo ano do conto. Pode-se dizer que uma entre todas as baratas clariceanas sobreviveu e instalou-se no guarda-roupa de um quarto de empregada ${ }^{3}$.

Tal como em "A quinta história" e o retorno das baratas, no romance $A$ paixão segundo G.H. as frases retornam, de modo a demarcar na escrita o impulso funcional da própria narrativa, ao mesmo tempo em que avança e recua.

De acordo com Dallenbach, a metáfora especular ficcional comporta uma subclassificação:

[...] la première, prospective, réfléchit avant terme l'histoire à venir; la deuxième, rétrospective, réfléchit après coup l'histoire accomplie; la troisième, retro-prospective, réfléchit l'histoire en découvrant les évenements anterieurs et les évenements postérieurs à son point d'acrage dans le récit. (DALLENBACH, 1977, p. 83)

Segundo a subclassificação acima, a metáfora especular de $A$ paixão segundo G.H. caracteriza-se por ser retroprospectiva, uma vez que espelha conteúdos já

\footnotetext{
${ }^{3}$ Essa ciranda de textos ainda inclui a atividade jornalística de Clarice Lispector, com as receitas para matar baratas, "Meio cômico, mas eficaz" e "Receita de assassinato (de baratas)", publicadas respectivamente nos jornais Comício e Diário da Noite, em 1952 e 1960. Tais textos revelam-se como verdadeiros embriões da escrita clariceana, uma vez que apresentam vestígios da contundência mais tarde potencializada na ficção.
} 


\section{Revista do SELL}

v. $4, n^{\circ} .2$

ISSN: $1983-3873$

mencionados e seus desdobramentos posteriores na retomada das frases, ocupando "uma posição intermediária entre aquilo que é sabido e aquilo que permanece a ser descoberto" (BAL, 1994, p. 50).

O mesmo procedimento também está presente no "Evangelho segundo São Lucas" e é denominado "inclusão": "procedimento que consiste em repetir as mesmas coisas no princípio e no final de uma passagem, para mostrar que se trata de um conjunto" (CHARPENTIER, 1992, p. 84 apud KANAAN, 2003, p. 135).

As repetições das frases permitem que Lispector lance mão da chamada "duplicação ao infinito", categoria tipificada pelos estudos de Dallenbach. Como exemplo desta categoria, temos a narrativa Contraponto, de Aldous Huxley (1894-1963). Na obra de Huxley, Philip Quarles, personagem escritor, imagina um romance em que um homem (também escritor) escreve um romance no qual um homem, por sua vez, também escreve. Prefigura-se, assim, o desdobramento infinito do enredo.

Dallenbach recorre aos estudos de C. E. Magny, que acrescenta outros exemplos de obras literárias, as quais fazem igualmente uso desse procedimento, salientando:

[...] ainsi, dans Ulysse, la conversation dans la bibliothèque au sujet d'Hamlet, et ou se trouvent repris 'en abyme' comme dit Gide (et Joyce, à qui plaisaient tous les langages techniques, eût sûrement aimé ce terme emprunté au blason) quelques un dês thèrmes majeurs du livre: particulier celui de la paternité, sous son double aspect, spirituel et temporel. (MAGNY apud DALLENBACH, 1977, p. 34)

O discurso de G.H surge ao leitor acompanhado por uma verdadeira indagação metafísica em um projeto de compreensão e revelação de um mundo que se concretiza: "Mas como me reviver? Se não tenho uma palavra natural a dizer. Terei que fazer a palavra como se fosse criar o que me aconteceu?" (LISPECTOR, 1998, p. 20).

É importante salientarmos que, no século $\mathrm{XX}$, destacou-se o aspecto de reflexão crítica da arte sobre si mesma, uma arte que, ao construir-se, discorre muitas vezes sobre o seu processo de construção. Nesse âmbito, o texto é tanto o produto da criação artística quanto a reflexão sobre o que seja arte e literatura.

Manejando os meandros da linguagem literária, o romance $A$ paixão segundo G.H avança, portanto, em direção à capacidade reflexiva, intervindo como metassignificação, o que permite à narrativa tomar-se a si mesma como tema: "Il rilievo teorico della pratica della mise en abyme si sviluppa secondo due fondamentale direttrici problematiche: la sua 


\section{Revista do SELL \\ v. $4, n^{\circ} .2$ \\ ISSN: $1983-3873$}

natura contestatoria dell'ordine del testo, il suo valore metacomunicativo" (TOMASSINI, 1990, p. 93).

Dessa interação narrativa surge, portanto, uma espécie de metadiscurso, confundindo a escritura e condensando o sentido da obra enquanto autorrepresentação: "Estou adiando. Sei que tudo o que estou falando é só para adiar - adiar o momento em que terei que começar a dizer, sabendo que nada mais me resta a dizer" (LISPECTOR, 1998, p. 22).

Ao analisar a escritura de Cortázar, Davi Arrigucci Júnior (2003) enfatiza a presença da destruição e do silêncio na tentativa de ir além dos limites da linguagem:

A exigência de se atingir o que as palavras não podem dizer acaba por exigir também a tematização do próprio ato de narrar, ou melhor, da sua possibilidade. É como se a narrativa se tornasse uma narrativa em busca de sua própria essência, centrando-se sobre si mesma. A narrativa de uma busca se faz uma busca da narrativa. Ao tematizar uma busca essencial, tematiza-se a si própria. (ARRIGUCCI-JÚNIOR, 2003, p. 23-24)

Ainda que trate da escrita de Júlio Cortázar, o ensaio de Davi Arrigucci Júnior é propício para o que estamos aqui tratando, uma vez que a obra clariceana também conta com um aspecto circular, oscilando entre os pólos da palavra e os limites do silêncio: "O indizível só me poderá ser dado através do fracasso de minha linguagem. Só quando falha a construção, é que obtenho o que não conseguiu" (LISPECTOR, 1998, p. 176).

Prestes a ruir no silêncio petrificado, o discurso de G.H. torna-se falho à medida em que avança.: "[...] Desnecessário dizer que o momento mais intenso do relato, a ingestão da barata, é irrepresentável, sendo apenas aludido pelo silêncio através do qual se presentifica" (ROSENBAUM, 1999, p. 153).

Nos apontamentos acerca do romance do século $X X$, Jean Yves-Tadié toma de empréstimo a expressão "obra aberta", retirada do conhecido estudo de Umberto Eco. Para o teórico italiano, "toda a obra de arte [...] é aberta pelo menos por poder ser interpretada de maneiras diferentes sem que seja alterada com isso a sua singularidade irredutível" (ECO, 1962 apud TADIÉ, 1990, p. 109).

Recorrendo aos estudos de Eco, Jean Yves-Tadié discute a estrutura do romance moderno, caracterizando-o pela abertura do sentido, ao lado da indeterminação e descontinuidade: "Reencontram-se assim, por felicidade, todas as filosofias da obra aberta, anônima, plural, desconstruída, em fragmentos, em movimento perpétuo, como discurso infinito, escrita do desastre" (TADIÉ, 1990, p. 120). 


\section{Revista do SELL}

v. $4, n^{\circ} .2$

ISSN: $1983-3873$

O sentido arquitetônico dado a essa construção é perpassado por inserções que reinventam o próprio desdobramento da gênese do romance, através de perturbações que quebram a fixação de um plano fechado, como se constituísse um "organismo vivo", nas palavras de Jean-Yves Tadié (1995, p. 263).

As considerações de Tadié confirmam o efeito de circularidade presente no texto clariceano como um aspecto consciente, uma espécie de preparação para o silêncio do discurso, concorrendo para o "drama da linguagem", tão bem descrito por Benedito Nunes: "[...] certas matrizes poéticas que indicam o movimento em círculo, a que antes nos referimos, da palavra ao silêncio e do silêncio à palavra" (NUNES, 1995, p. 135).

A estrutura circular e labiríntica da narrativa clariceana conduz o leitor ao eterno retorno, a uma volta contínua de um mesmo ponto, enredado por uma teia de sentidos e sensações infinitas, à semelhança da lógica das bonecas russas (matryhoskas) e das caixas chinesas, acopladas umas dentro das outras, em sinal de infinita retomada:

Esta espécie de presente de grego, que nos remete sempre a uma outra caixa para nos deixar, no final, com o nada do início, esta progressão que não avança, circunvoluções no labirinto, acaba por fazer reverter a busca sobre si mesma numa autoindagação da possibilidade de prosseguir. [...] defrontando-se consigo mesma, encaracola-se, volta-se contra si própria. (ARRIGUCCI JÚNIOR, 2003, p. 24-25)

E assim, o aspecto fragmentário da obra constata o desejo que se metaforiza pela busca da palavra. Embora o livro termine, a narrativa continua a se espraiar, com a apresentação dos travessões finais, que remetem ao início: "[...] A vida se me é, e eu não entendo o que digo. E então adoro " (LISPECTOR, 1998, p. 179).

\section{Considerações finais}

O presente artigo buscou realizar uma análise possível da narrativa especular de Clarice Lispector, apresentando como corpus o romance $A$ paixão segundo G.H.

A especularidade da obra clariceana caracteriza-se por certos contextos reincidentes, reencontros, reduplicações e repetições. É desse modo que as imagens das baratas voltam e a autora revela uma escrita com forte capacidade reflexiva, instaurando o movimento do sujeito que se procura.

O crítico Benedito Nunes já observara o recurso da repetição em Clarice Lispector, identificando-a como o "traço de mais largo espectro" (NUNES, 1995, p. 136) na obra da 


\section{Revista do SELL}

v. $4, n^{\circ} .2$

ISSN: $1983-3873$

escritora. Para o crítico, a repetição é um aspecto consciente, que concorre para o "drama da linguagem" na escrita de Clarice.

Ao lado da repetição, Nunes reconhece os paradoxos presentes no discurso de G.H. Segundo o estudioso, este recurso "constitui outro dos diferenciadores poéticos da prosa de Clarice Lispector" (NUNES, 1995, p. 143).

O processo repetitivo dos termos instaura a personagem gravitando em torno de uma busca, ou seja, um ser sem identidade, questionando-se acerca de seu próprio destino: "[...] a explicação de um enigma é a repetição do enigma" (LISPECTOR, 1998, p. 134).

Os enunciados paradoxais apresentam, portanto, o estado de espírito de G.H. e antecipam a experiência contraditória e única que ocorrerá no quarto dos fundos de seu apartamento.

O texto é semelhante a um labirinto em que escrever equivale a procurar, instituindo obsessivamente o eterno retorno, numa espécie de "processo em círculo, que termina para recomeçar, e cujo início não pode mais ser do que um retorno" (NUNES, 1995, p. 76).

A trajetória de G.H. é revelada paralelamente à construção de um "eu", ou seja, a partir do momento em que ela traça um itinerário dentro de sua casa, percebe-se o início de uma viagem rumo a um autoconhecimento, ao modo das narrativas poéticas:

L'itinéraire, le voyage dans le récit poétique, représente ainsi la dernière étape dune évolution qui va du voyage extérieur au voyage intérieur, et du voyage intérieur à un voyage à travers ces grands espaces vacants que les mots suffisent à engendrer. (TADIÉ, 1978, p. 67)

Nesse itinerário, tudo se duplica, espelhando-se em vários modos de ser e de estar, como algo que ora converge, ora diverge no espaço literário. E assim, o romance $A$ paixão segundo G.H. descortina uma dimensão especular e poética, a qual insiste na multiplicação de sentidos movimentada pelo ato de escrever que surge vivo, experimentando os limites da linguagem.

Vivenciando um percurso especular e errático, G.H. depara-se com a inominável e contraditória beleza contida na barata, ser que metaforiza a complexa condição humana.

Como conclusão, afirmamos ser a obra clariceana um elemento de transcendência na surpreendente quebra dos condicionadores que limitam o cotidiano, semelhante ao movimento da crônica "A surpresa": 


\section{Revista do SELL \\ v. $4, n^{\circ} .2$ \\ ISSN: $1983-3873$}

Olhar-se ao espelho e dizer-se deslumbrada: Como sou misteriosa. Sou tão delicada e forte. E a curva dos lábios manteve a inocência. Não há homem ou mulher que por acaso não se tenha olhado ao espelho e se surpreendido consigo próprio. Por uma fração de segundo a gente se vê como a um objeto a ser olhado. A isto se chamaria talvez de narcisismo, mas eu chamaria de: alegria de ser. Alegria de encontrar na figura exterior os ecos da figura interna: ah, então é verdade que eu não me imaginei, eu existo. (LISPECTOR, 1999b, p. 23)

\section{Referências}

ABDALA-JÚNIOR, Benjamin; CAMPEDELLI, Samira Youssef. Vozes da Crítica. In: $A$ paixão segundo G.H. Ed. Crítica/Benedito Nunes, coordenador. Paris: Association Archives de la littérature latinoaméricaine, des Caraibes et africaine du XXe siécle; Brasília, DF: CNPQ, 1988. p. 196-206, (Col. Arquivos, 13).

ARRIGUCCI-JÚNIOR, Davi. O escorpião encalacrado: a poética da destruição em Júlio Cortázar. São Paulo: Cia das Letras, 2003.

BAL, Mieke. Reflections on reflection: the mise en abyme. In: BAL, Mieke. On meaningmaking: essays in semiotics. Sonoma, CA: Polebridge Press, 1994, p.45-58.

BARTHES, Roland. A morte do autor. In: BARTHES, Roland. O rumor da língua. Tradução de Mário Laranjeira. São Paulo: Martins Fontes, 2004, p. 57-64.

DALLENBACH, Lucien. Mosaïques: un objet esthétique à rebondissements. Paris:

Editions du Seuil (Poétique), 2001.

. Intertexto e autotexto. In: DALLENBACH, Lucien et alii. Intertextualidades.

Tradução de Clara Crabbé Rocha. Coimbra: Almedina, 1979, p. 51-76.

. Le récit spéculaire: essai sur la mise en abyme. Paris: Editions du Seuil (Poétique), 1977.

DURAND, Gilbert. As estruturas antropológicas do imaginário: introdução à arquetipologia geral. Tradução de Hélder Godinho. São Paulo: Martins Fontes, 1997.

GARCIA, Maria José Ladeira. A mise en abyme em Inventário do inútil, de Elias José. Verbo de Minas, Juiz de Fora, n. 13, p. 127-138, jan/jun 2008.

GENETTE, Gerard. Palimpsestes: la littérature au second degré. Paris: Seuil, 1982.

GIDE, Andre. Os moedeiros falsos. Tradução de Celina Portocarrero. Rio de Janeiro: Francisco Alves, 1983.

GOULET, Alain. L'auteur mis en abyme (Valéry et Gide). Lettres Françaises: revista da área de Língua e Literatura Francesa, Araraquara/FCL-UNESP/Laboratório Editorial, n. 7, p.39-58, 2006. 


\section{Revista do SELL}

v. $4, n^{\circ} .2$

ISSN: $1983-3873$

KAHN, Daniela Mercedes. As mil e uma formas do mesmo. In: KAHN, Daniela Mercedes. $A$ via crucis do outro: identidade e alteridade em Clarice Lispector. São Paulo: Associação Editorial Humanitas: Fapesp, 2005, p. 25-38.

KANAAN, Dany Al-Behy. À escuta de Clarice Lispector: entre o biográfico e o literário: uma ficção possível. São Paulo: EDUC, 2003. p. 134-144.

JENNY, Laurent. A estratégia da forma. In: JENNY, Laurent et al. Intertextualidades. Tradução de Clara Crabbé Rocha. Coimbra: Almedina, 1979, p. 5-49.

LISPECTOR, Clarice. A quinta história. In: LISPECTOR, Clarice. A legião estrangeira. Rio de Janeiro: Rocco, 1999a, p. 74-76.

A surpresa. In: LISPECTOR, Clarice. A descoberta do mundo. Rio de Janeiro: Rocco, 1999b, p. 23.

A paixão segundo G.H. Rio de Janeiro: Rocco, 1998.

NUNES, Benedito. O drama da linguagem. 2. ed. São Paulo: Ática, 1995.

Introdução do coordenador. In: A paixão segundo G.H. Ed. Crítica/Benedito Nunes, coordenador. Paris: Association Archives de la littérature latino-americaine, des Caraibes et africaine du XXe siècle; Brasília, DF: CNPQ, 1988. p. 24-33, (Col. Arquivos, 13).

PAZ, Octavio. O arco e a lira. 2. ed. Tradução de Olga Savary. Rio de Janeiro: Nova Fronteira, 1995.

ROSENBAUM, Yudith. Do mal secreto. In: ROSENBAUM, Yudith. Metamorfoses do mal: uma leitura de Clarice Lispector. São Paulo: Editora da Universidade de São Paulo: Fapesp, 1999, p. 121-136. (Ensaios de Cultura, 17).

SÁ, Olga de. A escritura de Clarice Lispector. 3. ed. Petrópolis: Vozes; Lorena: Faculdades Integradas Teresa D'Avila, 2000.

SARAIVA, António José; LOPES, Óscar . História da Literatura Portuguesa. 4 ed. Porto: Porto Ed., 1969.

TADIÉ, Jean-Yves. Proust et le roman. Paris: Gallimard, 1995. . O romance no século XX. Tradução de Miguel Serras. Lisboa: Publicações Dom Quixote, 1990. . Le récit poétique. Paris: Presses Universitaires de France, 1978.

TASCA, Norma. A lógica dos efeitos passionais. In: A paixão segundo G.H. Ed. Crítica/Benedito Nunes, coordenador. Paris: Association de la littérature latino-américaine, des Caraibes et africaine du siécle XXe; Brasília, DF: CNPQ, 1988. p. 258-288. (Col. Arquivos, 13). 


\section{Revista do SELL \\ v. $4, n^{\circ} .2$ \\ ISSN: $1983-3873$}

TODOROV, Tzvetan. Os homens-narrativas. In: TODOROV, Tzvetan. As estruturas narrativas. Tradução de Moysés Baumstein. São Paulo: Perspectiva, 1969, p. 119-133.

TOMASSINI, Giovanni Battista. La mise en abyme. In: TOMASSINI, Giovanni Battista. II racconto nel racconto: analisi teorica dei procedimenti d'inserzione narrativa. Roma: Bulzoni, 1990. 